\title{
C-Reactive Protein and Absolute Lymphocyte Count Can Predict Overall Survival of Patients Treated With Eribulin
}

\author{
ATSUSHI SATA ${ }^{1,2}$, REIKO FUKUI ${ }^{1}$, YOSHIMASA MIYAGAWA ${ }^{1}$, AYAKO BUN ${ }^{1}$, HIROMI OZAWA $^{1}$, \\ YUKIE FUJIMOTO $^{1}$, TOMOKO HIGUCHI $^{1}$, MICHIKO IMAMURA ${ }^{1}$ and YASUO MIYOSHI ${ }^{1}$ \\ ${ }^{1}$ Department of Surgery, Division of Breast and Endocrine Surgery, \\ Hyogo College of Medicine, Nishinomiya, Japan; \\ ${ }^{2}$ Department of Breast Surgery, Yao Municipal Hospital, Yao, Japan
}

\begin{abstract}
Background/Aim: We investigated the efficacy of neutrophil-to-lymphocyte ratio (NLR), absolute lymphocyte count $(A L C)$, and $C$-reactive protein $(C R P)$ in predicting overall survival of metastatic breast cancer patients treated with eribulin. Patients and Methods: Overall, 74 patients treated with eribulin were enrolled and their baseline levels of $N L R$, ALC, and CRP retrieved. Cutoff values of NLR, ALC, and

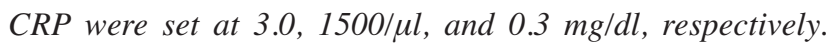
Overall survival (OS) was compared according to marker levels. Results: The OS of NLR-low, ALC-high, and CRP-low groups at baseline was significantly longer than that of NLRhigh, ALC-low, and CRP-high groups ( $p=0.0027, p=0.0013$, and $p=0.0164$, respectively). The combination of $A L C$ and CRP was significantly associated with OS by multivariate analysis $(p=0.048)$. Conclusion: Baseline levels of NLR, ALC, and CRP were significantly associated with OS in patients treated with eribulin. The combination of ALC and CRP improved the predictive efficacy compared to individual markers.
\end{abstract}

Chemotherapy for locally advanced or metastatic breast cancer (MBC) is an essential treatment choice in daily clinical practice. Usually, the indication for chemotherapy is based on factors such as tumor subtypes and characteristics, metastatic sites, existing visceral crisis, and previous therapies for adjuvant or metastatic settings (1). Although predictive biomarkers are required to assess the efficacy of

This article is freely accessible online.

Correspondence to: Yasuo Miyoshi, Department of Surgery, Division of Breast and Endocrine Surgery, Hyogo College of Medicine, Mukogawa-cho 1-1, Nishinomiya, Hyogo 663-8501, Japan. Tel: +81 798456374, Fax: +81 798456252, e-mail: ymiyoshi@hyo-med.ac.jp

Key Words: Breast cancer, absolute lymphocyte count, c-reactive protein, eribulin, overall survival. chemotherapeutic agents, no such biomarker has been identified for MBC.

Eribulin, a non-taxane inhibitor of microtubule dynamics, is an effective agent yielding longer overall survival (OS) in MBC patients as compared with treatments of physician's choice (TPC) in the Phase III EMBRACE trial (2). Interestingly, OS was improved without benefit in terms of progression-free survival (PFS) between the eribulin and TPC arms. This impact on OS rather than PFS was further confirmed in the Phase III study 301 , in which eribulin was compared with capecitabine in MBC patients (3) and real-world data $(4,5)$.

The precise mechanisms by which eribulin improves OS rather than PFS are currently unclear. It has been demonstrated that eribulin suppresses epithelial-mesenchymal transition (EMT), which plays an important role in tumor progression and metastasis (6). This mechanism seems to stem from the inhibition of TGF- $\beta$-mediated Snail expression (7) or regulation of E-cadherin localization (8). The second mechanism related to eribulin treatment is vascular normalization within a tumor. Since eribulin reverses the hypoxic condition of the tumor microenvironment through vascular remodeling (9), this action also reduces the phenotype of EMT by suppressing hypoxia-inducible factor$1 \alpha(\operatorname{HIF} 1 \alpha)(10)$. Based on these studies, it is possible that eribulin improves OS by suppressing EMT directly and indirectly through vascular remodeling, $(11,12)$.

Recently, the involvement of the immune system has been demonstrated to contribute to OS in metastatic tumors (13). If vascular normalization induced by eribulin treatment improves the immune microenvironment in breast cancer, longer OS could be achieved by mediating an immune reaction against breast cancer (14). In line with this hypothesis, several studies have demonstrated that the neutrophil-to-lymphocyte ratio (NLR), a peripheral immune-related marker, was significantly associated with PFS in MBC patients treated with eribulin. Miyagawa et al. reported that PFS was significantly longer in the baseline NLR $<3$ group than in the NLR $\geq 3$ group in patients treated with eribulin [hazard ratio $(\mathrm{HR})=0.37 ; 95 \%$ 
confidence interval $(C I)=0.18-0.71 ; p=0.0032]$ (15). Similarly, worse PFS was observed in patients with high NLR compared to that in those with low NLR, according to reports by Myojin et al. (NLR >3.3 vs. $\leq 3.3$; adjusted HR, 2.03; 95\% CI=1.29$3.17 ; p=0.003)(16)$ and Ueno et al. (NLR $\geq 5.0 v s .<5.0$; adjusted $\mathrm{HR}=1.78 ; 95 \% \mathrm{CI}=1.00-3.15)$ (17). In addition, the Phase III EMBRACE study showed that absolute lymphocyte count (ALC) was a predictive factor for eribulin but not for TPC (18).

Although NLR and ALC are immune-related peripheral markers, their significance as predictive factors for the efficacy of eribulin may not be identical; the EMBRACE study demonstrated that both NLR and ALC were predictive factors for eribulin and that NLR but not ALC was a predictor for TPC (18). Ueno et al. classified patients treated with eribulin according to NLR and ALC levels into three groups: unfavorable (NLR $\geq 5$ ), intermediate (ALC $<1500 / \mu 1$, NLR $<5.0$ ), and favorable $($ ALC $\geq 1500 / \mu l)$ and showed different PFS in these three groups $(p=0.006)(17)$. Thus, even though ALC is a predictive factor for eribulin, identification of further subgroups in which eribulin has efficacy in terms of OS is needed.

In addition to NLR and ALC, C-reactive protein (CRP), an inflammatory marker, is known to be a prognostic factor for MBC (19). The purpose of this study, therefore, was to identify the predictive efficacy of NLR, ALC, and CRP for $\mathrm{OS}$ in $\mathrm{MBC}$ patients treated with eribulin using a combination of these markers.

\section{Patients and Methods}

Patient eligibility and clinical factors. All 82 patients who were treated with eribulin for locally advanced or metastatic breast cancer between August 2011 and August 2019 at Hyogo College of Medicine Hospital were consecutively screened for recruitment into this study. Of the 82 patients, those treated with concurrent anti-human epidermal growth factor receptor 2 (HER2) therapy $(n=5)$, or received treatment of less than one cycle $(n=2)$, or lacked CRP data $(n=1)$ were excluded. Patients with HER2-positive breast cancer were eligible for treatment with eribulin monotherapy without anti-HER2 therapy; finally, 74 patients were included in this retrospective study. A total of 58 patients were included in a previous study by our group (15) and the data were updated in April 2020.

All patients were diagnosed with breast cancer using histopathology and cancers were considered to be estrogen receptor (ER)-positive and progesterone receptor (PR)-positive if nuclear staining was $1 \%$ or more. Cases were considered HER2-positive if the immunohistochemistry (IHC) score was $3+$; in cases of IHC score 2+, we confirmed HER 2 amplification by fluorescence in-situ hybridization. Subtypes were classified as ER-positive and HER2negative, ER-negative and HER2-negative, and HER2-positive. One patient had two tumors (ER-positive/HER2-negative and ERnegative/HER2-negative). Patients with stage IV and recurrent tumors were 18 and 56, respectively, and patients with and without visceral metastasis were 34 and 40, respectively, (Table I). Adjuvant or neoadjuvant chemotherapy was administered to 25 patients. The median number of previous chemotherapy regimens for advanced or metastatic breast cancer was one (range $=0-8$ ).

The ethics committee of the Hyogo College of Medicine approved the present study (approval no. 1969) in accordance with the Declaration of Helsinki. As the present study collected clinical data retrospectively, the need for written informed consent was waived.

Eribulin treatment and outcome evaluation. Eribulin was administered intravenously at $1.4 \mathrm{mg} / \mathrm{m}^{2}$ over $5 \mathrm{~min}$ on days 1 and 8 of each 21-day cycle. In patients who were unable to tolerate this dose and showed adverse events, the eribulin dose was reduced to 1.1 or $0.7 \mathrm{mg} / \mathrm{m}^{2}$. Administration was delayed if decreased neutrophil count or increased liver enzyme levels were observed. Eribulin treatment was continued until tumor progression $(n=62)$ or an intolerable adverse event $(n=9)$ was observed and is ongoing in three cases. PFS was defined as the period from the start of eribulin therapy until disease progression or death due to any reason (median, 4.3 months; range=0.7-29.2 months). We calculated OS from the start of eribulin treatment to death from any reason (median, 14.2 months; range=1.5-71.1 months).

Blood tests for NLR, ALC, and CRP. We collected baseline data on peripheral blood counts, including white blood cell, neutrophil, and lymphocyte levels, measured using automated hematology analyzers (XN-9000, XN-1000, and XE-5000, Sysmex Corporation, Kobe, Japan). Based on these data, we calculated NLR by dividing the number of neutrophils by the number of lymphocytes. CRP levels were measured with the LABOSPECT008 (Hitachi HighTechnologies Corporation, Tokyo, Japan). All blood tests were performed on the same day or one day before the first administration of eribulin. The cutoff values of NLR and ALC were set at 3 and $1500 / \mu 1$, respectively, according to previous studies (15, 18 ); cases below the cutoff values were defined as NLR-low and ALC-low, respectively and those above the cutoff values as NLRhigh and ALC-high, respectively. Using the normal range of CRP $(<0.3 \mathrm{mg} / \mathrm{dl})$ as a cutoff value, cases below and above $0.3 \mathrm{mg} / \mathrm{dl}$ were classified as CRP-low and CRP-high, respectively.

Statistical analysis. Relationships between clinicopathological characteristics and NLR, ALC, or CRP levels were determined by Fisher's exact test or the Wilcoxon rank-sum test. We used KaplanMeier plots of PFS or OS for different groups of NLR, ALC, and CRP levels, and statistical analyses were performed using log-rank tests. Univariate and multivariate analyses for OS were calculated using a Cox proportional-hazards model to obtain the HR and $95 \%$ CI. $p$-Values of less than 0.05 were considered to be statistically significant. All statistical calculations were performed using JMP Pro 13 (SAS Institute Inc., Cary, NC, USA).

\section{Results}

Clinicopathological characteristics of breast cancers according to NLR, ALC, and CRP levels. Breast cancers were divided according to NLR levels (low, $n=33$; high, $n=41$ ), ALC levels (low, $n=53$; high, $n=21$ ), and CRP levels (low, $\mathrm{n}=33$; high, $\mathrm{n}=41$ ) as shown in Table I. Patients with low CRP were significantly younger than those with high CRP (median 58 years $v s$. 64 years; $p=0.022$ ). Patients were more likely to 
Table I. Clinicopathological characteristics of breast cancers according to neutrophil-to-lymphocyte ratio (NLR), absolute lymphocyte count (ALC), or C-reactive protein $(C R P)$.

\begin{tabular}{|c|c|c|c|c|c|c|c|c|c|}
\hline & $\begin{array}{l}\text { NLR-low }^{a} \\
(\mathrm{n}=33)\end{array}$ & $\begin{array}{l}\text { NLR-high } \\
\quad(\mathrm{n}=41)\end{array}$ & $p$-Value & $\begin{array}{l}\text { ALC-lowb } \\
(\mathrm{n}=53)\end{array}$ & $\begin{array}{l}\text { ALC-high } \\
\quad(\mathrm{n}=21)\end{array}$ & $p$-Value & $\begin{array}{l}\text { CRP-low }^{\mathrm{c}} \\
(\mathrm{n}=33)\end{array}$ & $\begin{array}{l}\text { CPR-high } \\
(\mathrm{n}=41)\end{array}$ & $p$-Value \\
\hline \multicolumn{10}{|l|}{ Age (years; } \\
\hline \multicolumn{10}{|c|}{ Menopausal status ${ }^{\mathrm{d}}$} \\
\hline Pre- & $5(38.5)^{e}$ & $8(61.5)$ & \multirow[t]{2}{*}{0.764} & $6(46.2)$ & $7(53.8)$ & \multirow[t]{2}{*}{0.035} & $8(61.5)$ & $5(38.5)$ & \multirow[t]{2}{*}{0.219} \\
\hline Post- & $27(45.0)$ & $33(55.0)$ & & $47(78.3)$ & $13(21.7)$ & & $24(40.0)$ & $36(60.0)$ & \\
\hline \multicolumn{10}{|c|}{ Estrogen receptor ${ }^{\mathrm{f}}$} \\
\hline Positive & $24(44.4)$ & $30(55.6)$ & \multirow[t]{2}{*}{0.999} & $35(64.8)$ & $19(35.2)$ & \multirow[t]{2}{*}{0.045} & $21(38.9)$ & $33(61.1)$ & \multirow[t]{2}{*}{0.184} \\
\hline Negative & $8(42.1)$ & $11(57.9)$ & & $17(89.5)$ & $2(10.5)$ & & $11(57.9)$ & $8(42.1)$ & \\
\hline \multicolumn{10}{|c|}{ Progesterone receptor ${ }^{\mathrm{f}}$} \\
\hline Positive & $20(50.0)$ & $20(50.0)$ & \multirow[t]{2}{*}{0.343} & $27(67.5)$ & $13(32.5)$ & \multirow[t]{2}{*}{0.604} & $18(45.0)$ & $22(55.0)$ & \multirow[t]{2}{*}{0.999} \\
\hline Negative & $12(36.4)$ & $21(63.6)$ & & $25(75.8)$ & $8(24.2)$ & & $14(42.4)$ & $19(57.6)$ & \\
\hline \multicolumn{10}{|l|}{ HER2 status } \\
\hline Negative & $31(43.7)$ & $40(56.3)$ & \multirow[t]{2}{*}{0.583} & $51(71.8)$ & $20(28.2)$ & \multirow[t]{2}{*}{0.999} & $32(45.1)$ & $39(54.9)$ & \multirow[t]{2}{*}{0.999} \\
\hline Positive & $2(66.7)$ & $1(33.3)$ & & $2(66.7)$ & $1(33.3)$ & & $1(33.3)$ & $2(66.7)$ & \\
\hline \multicolumn{10}{|l|}{ Subtypesf } \\
\hline ER+/HER2- & $20(50.0)$ & $20(50.0)$ & \multirow[t]{3}{*}{0.295} & $27(67.5)$ & $13(32.5)$ & \multirow[t]{3}{*}{0.674} & $18(45.0)$ & $22(55.0)$ & \multirow[t]{3}{*}{0.879} \\
\hline ER-/HER2- & $10(33.3)$ & $20(66.7)$ & & $23(76.7)$ & $7(23.3)$ & & $13(33.3)$ & $17(56.7)$ & \\
\hline HER $2+$ & $2(66.7)$ & $1(33.3)$ & & $2(66.7)$ & $1(33.3)$ & & $1(33.3)$ & $2(66.7)$ & \\
\hline \multicolumn{10}{|c|}{ De novo or recurrent tumor } \\
\hline De novo & $5(27.8)$ & $13(72.2)$ & \multirow[t]{2}{*}{0.112} & $13(72.2)$ & $5(27.8)$ & \multirow[t]{2}{*}{0.999} & $6(33.3)$ & $12(66.7)$ & \multirow[t]{2}{*}{0.292} \\
\hline Recurrent & $28(50.0)$ & $28(50.0)$ & & $40(71.4)$ & $16(28.6)$ & & $27(48.2)$ & $29(51.8)$ & \\
\hline \multicolumn{10}{|l|}{ Metastatic site } \\
\hline Visceral & $15(44.1)$ & 19 (55.9) & \multirow[t]{2}{*}{0.999} & 24 (70.6) & $10(29.4)$ & \multirow[t]{2}{*}{0.999} & 18 (52.9) & $16(47.1)$ & \multirow[t]{2}{*}{0.242} \\
\hline Non-visceral & $18(45.0)$ & $22(55.0)$ & & $29(72.5)$ & $11(27.5)$ & & $15(37.5)$ & $25(62.5)$ & \\
\hline Adjuvant or neo & & & & & & & & & \\
\hline No & $12(38.7)$ & $19(61.3)$ & 0.106 & $25(80.6)$ & $6(19.4)$ & 0.137 & $12(38.7)$ & $19(61.3)$ & 0.178 \\
\hline Yes & $16(64.0)$ & $9(36.0)$ & & $15(60.0)$ & $10(40.0)$ & & $15(60.0)$ & $10(40.0)$ & \\
\hline $\begin{array}{l}\text { Number of prior } \\
\text { regimens for adv } \\
\text { metastatic breast }\end{array}$ & & & & & & & & & \\
\hline 0 and 1 & $25(61.0)$ & $16(39.0)$ & 0.002 & $21(51.2)$ & $20(48.8)$ & $<0.0001$ & $21(51.2)$ & $20(48.8)$ & 0.244 \\
\hline 2 or more & $8(24.2)$ & $25(75.8)$ & & $32(97.0)$ & $1(3.0)$ & & $12(36.4)$ & $21(63.6)$ & \\
\hline
\end{tabular}

${ }^{a}$ Neutrophil-to-lymphocyte ratio high: $\geq 3$, low: $<3$; babsolute lymphocyte count high: $\geq 1500 / \mu 1$, low: $<1500 / \mu$; ${ }^{\mathrm{c} C}$-reactive protein high: $\geq 0.3 \mathrm{mg} / \mathrm{dl}$, low: $<0.3 \mathrm{mg} / \mathrm{dl}$; ${ }^{\mathrm{d} O n e}$ patient was male; ${ }^{\mathrm{e}}(\%)$; ${ }^{\mathrm{f} O n e}$ patient had two tumors (positive and negative); HER2: human epidermal growth factor receptor 2; ER: estrogen receptor.

be premenopausal $(53.8 \%$ vs. $21.7 \% ; p=0.035)$ and estrogen receptor-positive $(35.2 \%$ vs. $10.5 \%$; $p=0.045)$ in the ALC-high group than in the ALC-low group. Patients with two or more previous chemotherapy regimens for $\mathrm{MBC}$ were frequent in the NLR-high $(75.8 \%$ vs. 39.0\%; $p=0.002)$ and ALC-low groups $(97.0 \%$ vs. $51.2 \% ; p<0.0001)$, but no difference was observed between the CRP groups ( $p=0.244)$. There was no significant association between NLR, ALC, or CRP levels and other clinicopathological characteristics, including PR and HER2 status, subtypes, de novo or recurrence, metastatic sites, and adjuvant or neoadjuvant chemotherapy.

Progression-free survival and overall survival of patients treated with eribulin according to baseline NLR, ALC, and $C R P$ levels. Patients in the NLR-low group had significantly longer PFS $(\mathrm{HR}=0.444 ; 95 \% \mathrm{CI}=0.253-0.759 ; p=0.0028)$ and OS $(\mathrm{HR}=0.394 ; 95 \% \mathrm{CI}=0.203-0.726 ; p=0.0027)$ than those in the NLR-high group (Figure 1A, B). Marginally longer PFS and significantly longer OS were observed in patients of the ALC-high group $(\mathrm{HR}=0.586 ; 95 \% \mathrm{CI}=0.315-1.035 ; p=0.073$ and $\mathrm{HR}=0.300 ; 95 \% \mathrm{CI}=0.129-0.617$, respectively; $p=0.0013$; Figure 1C, D). Similarly, there were significantly longer PFS and $\mathrm{OS}$ in patients of the CRP-low group $(\mathrm{HR}=0.514$; $95 \% \mathrm{CI}=0.297-0.873 ; \quad p=0.0132$ and $\mathrm{HR}=0.483$; $95 \% \mathrm{CI}=0.257-0.875 ; p=0.0164$; Figure $1 \mathrm{E}, \mathrm{F})$. Next, we compared OS for combinations of the different NLR, ALC, and CRP levels, for example NLR-high and ALC-high, NLRhigh and ALC-low, etc. (Figure 2). The OS of patients common to the NLR-high and ALC-low group $(n=37$; $p=0.0013$; Figure 2A) and NLR-high and CRP-high group 
(A) Progression-free survival (NLR)

$\mathrm{HR}=0.444 ; 95 \% \mathrm{Cl}=0.253-0.759$

$p=0.0028$

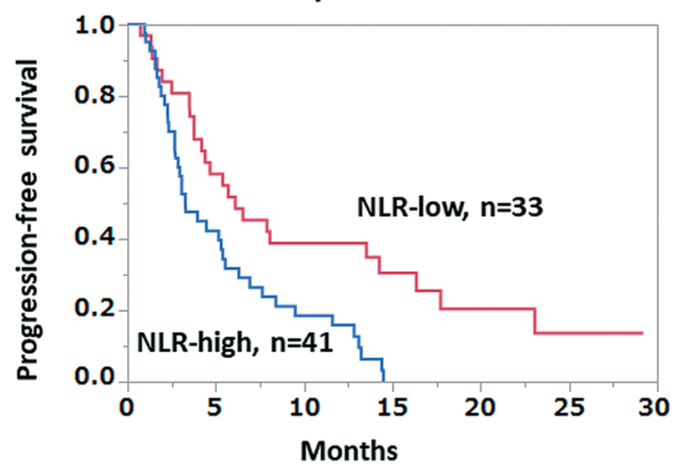

No. at risk

$\begin{array}{cccccccc}\text { NLR-low } & 33 & 18 & 11 & 6 & 3 & 3 & 0 \\ \text { NLR-high } & 41 & 16 & 7 & 0 & 0 & 0 & 0\end{array}$

(C) Progression-free survival (ALC)

$\mathrm{HR}=0.586 ; 95 \% \mathrm{Cl}=0.315-1.035$

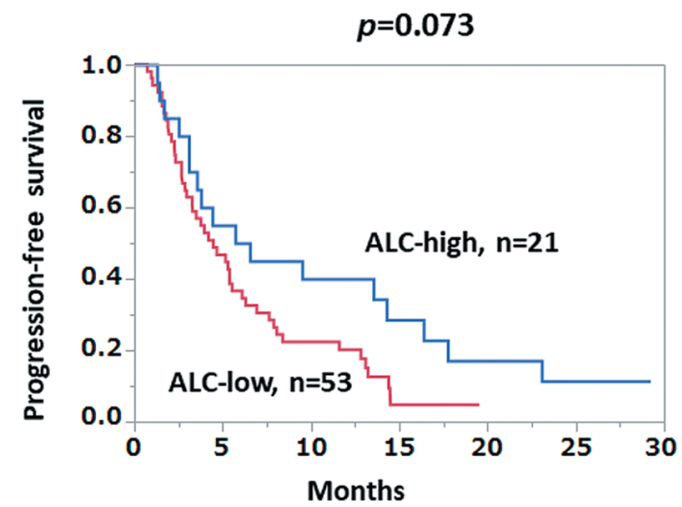

No. at risk

$\begin{array}{lrrrrrrr}\text { ALC-high } & 21 & 11 & 8 & 5 & 3 & 2 & 0 \\ \text { ALC-low } & 53 & 23 & 10 & 1 & 0 & 0 & 0\end{array}$

(E) Progression-free survival (CRP)

$\mathrm{HR}=0.514 ; 95 \% \mathrm{Cl}=0.297-0.873$

$p=0.0132$

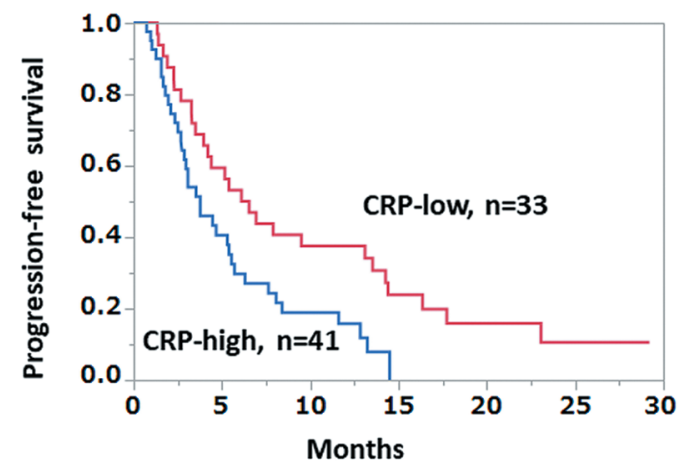

No. at risk

$\begin{array}{llllllll}\text { CRP-low } & 33 & 19 & 12 & 6 & 3 & 2 & 0 \\ \text { CRP-high } & 41 & 15 & 6 & 0 & 0 & 0 & 0\end{array}$
(B) Overall survival (NLR)

$\mathrm{HR}=0.394 ; 95 \% \mathrm{Cl}=0.203-0.726$

$p=0.0027$

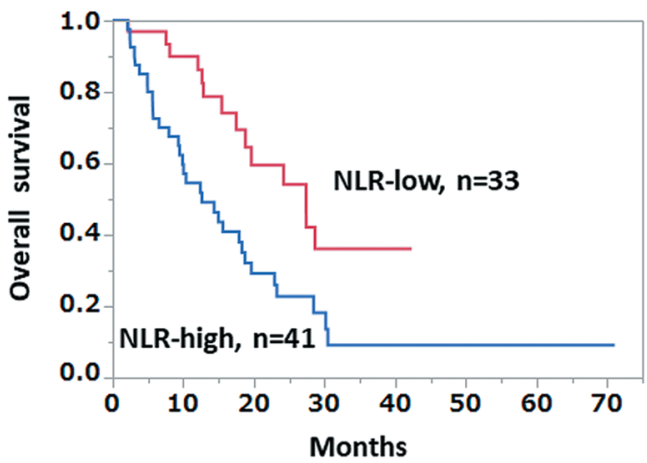

No. at risk

$\begin{array}{lllllllll}\text { NLR-low } & 33 & 25 & 12 & 6 & 2 & 0 & 0 & 0\end{array}$

(D) Overall survival (ALC)

$\mathrm{HR}=0.300 ; 95 \% \mathrm{Cl}=0.129-0.617$

$p=0.0013$

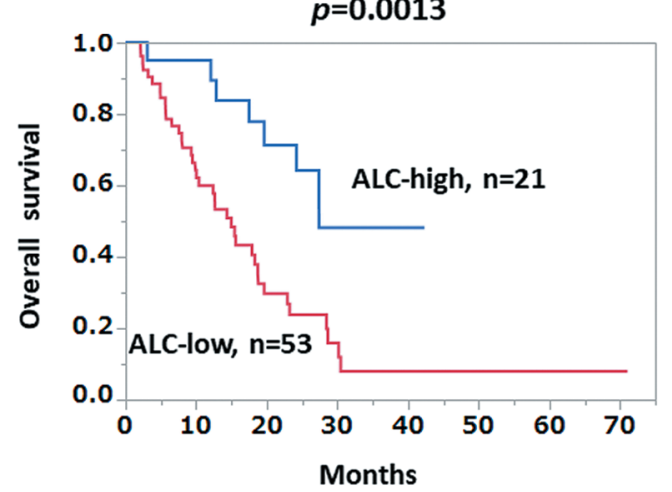

No. at risk

$\begin{array}{lllllllll}\text { ALC-high } & 21 & 18 & 10 & 6 & 2 & 0 & 0 & 0 \\ \text { ALC-low } & 53 & 30 & 11 & 4 & 1 & 1 & 1 & 1\end{array}$

(F) Overall survival (CRP)

$\mathrm{HR}=0.483 ; 95 \% \mathrm{Cl}=0.257-0.875$

$p=0.0164$

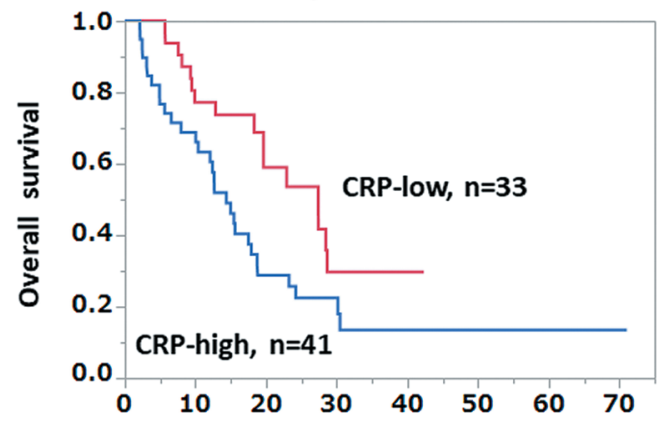

Months

No. at risk

$\begin{array}{lllllllll}\text { CRP-low } & 33 & 23 & 12 & 5 & 2 & 0 & 0 & 0\end{array}$ 
( $\mathrm{n}=29 ; p=0.0112$; Figure 2B) was shorter than that of the other groups. Similarly, OS was significantly shorter in the group of patients with low ALC and high CRP levels than that in the other groups of patients $(n=32 ; p=0.0013$; Figure $2 \mathrm{C})$.

Univariate and multivariate analyses for OS of patients treated with eribulin. Predictive significance for OS was calculated by univariate analysis (Table II). The number of prior chemotherapy regimens was significantly associated with OS $(\mathrm{HR}=3.443 ; 95 \% \mathrm{CI}=1.899-6.366 ; p<0.0001)$. In addition, high NLR (HR=2.539; 95\%CI=1.378-4.925; $p=0.018)$, low ALC $(\mathrm{HR}=3.332 ; 95 \% \mathrm{CI}=1.620-7.767$; $p=0.0007)$, and high CRP $(\mathrm{HR}=2.071 ; 95 \% \mathrm{CI}=1.143-3.896$; $p=0.018)$ were significant predictive factors for OS. Similarly, high NLR and low ALC (HR=3.178; 95\% CI=1.733-6.087; $p=0.0002)$, high NLR and high CRP $(\mathrm{HR}=2.173 ; 95 \% \mathrm{CI}=1.212-3.899 ; p=0.010)$, and low ALC and high $\mathrm{CRP}(\mathrm{HR}=2.795 ; 95 \% \mathrm{CI}=1.555-5.098 ; p=0.0006)$ were significantly associated with worse OS.

Multivariate analysis adjusted for menopausal status, subtypes, de novo or recurrence, metastatic site, administration of adjuvant or neoadjuvant chemotherapy, and number of prior chemotherapy regimens, NLR, ALC, and CRP levels were not significantly associated with OS (Table III). As for the combination of these markers, the combination of ALC and CRP was significantly and independently associated with OS by multivariate analysis (adjusted $\mathrm{HR}=1.984 ;$ 95\% CI=1.005-3.914; $p=0.048$ for ALC-low and CRP-high group; Table III).

Association between CRP levels and neutrophil counts, lymphocyte counts, and NLR levels. Neutrophil counts were significantly lower in the CRP-low group (median: 2791/ $\mu$; range $=1760-6872 / \mu \mathrm{l}$ ) than in the $\mathrm{CRP}$-high group (median: $3775 / \mu \mathrm{l} ;$ range $=1676-19399 / \mu 1 ; p=0.0049 ;$ Figure $3 \mathrm{~A})$.

$\leftarrow$

Figure 1. Progression-free survival (PFS) of patients according to baseline levels of neutrophil-to-lymphocyte ratio (NLR) (A). PFS was significantly longer in patients with low NLR than in those with high $N L R$ ( $p=0.0028)$. Overall survival $(O S)$ of patients according to baseline NLR levels $(B)$. OS was significantly longer in patients with low NLR than in those with high NLR $(p=0.0027)$. PFS of patients according to baseline levels of absolute lymphocyte count $(A L C)(C)$. PFS was not significantly different ( $p=0.073$ ). OS of patients according to baseline ALC levels $(D)$. OS was significantly longer in patients with high ALC than in those with low ALC $(p=0.0013)$. PFS of patients according to baseline levels of C-reactive protein (CRP) (E). PFS was significantly longer in patients with low CRP than in those with high CRP ( $p=0.0132)$. OS of patients according to baseline CRP levels $(F)$. OS was significantly longer in patients with low CRP than in those with high CRP ( $p=0.0164)$. NLR-high $\geq 3, N L R$-low $<3$; ALC-high $\geq 1500 / \mu l$, ALC-low $<1500 / \mu l$; CRP-high $\geq 0.3 \mathrm{mg} / \mathrm{dl}$, CRP-low $<0.3 \mathrm{mg} / \mathrm{dl}$.
Table II. Univariate analysis of overall survival.

\begin{tabular}{|c|c|c|c|}
\hline & $\mathrm{n}$ & $\operatorname{HR}(95 \% \mathrm{CI})^{\mathrm{a}}$ & $p$-Value \\
\hline \multicolumn{4}{|c|}{ Menopausal status ${ }^{b}$} \\
\hline Pre- & 13 & 1.00 & \\
\hline Post- & 60 & $2.032(0.927-5.353)$ & 0.079 \\
\hline \multicolumn{4}{|l|}{ Estrogen receptor ${ }^{\mathrm{c}}$} \\
\hline Positive & 54 & 1.00 & \\
\hline Negative & 19 & $1.347(0.693-2.491)$ & 0.367 \\
\hline \multicolumn{4}{|c|}{ Progesterone receptor ${ }^{\mathrm{c}}$} \\
\hline Positive & 40 & 1.00 & \\
\hline Negative & 33 & $1.269(0.709-2.280)$ & 0.421 \\
\hline \multicolumn{4}{|l|}{ HER2 status } \\
\hline Negative & 71 & 1.00 & \\
\hline Positive & 3 & $1.212(0.197-3.984)$ & 0.798 \\
\hline \multicolumn{4}{|l|}{ Subtype $e^{c}$} \\
\hline ER+/HER2- & 40 & 1.00 & \\
\hline ER-/HER2- & 30 & $1.262(0.695-2.291)$ & 0.441 \\
\hline HER2+ & 3 & $1.346(0.214-4.637)$ & 0.701 \\
\hline \multicolumn{4}{|c|}{ De novo or recurrent tumor } \\
\hline De novo & 18 & 1.00 & \\
\hline Recurrent & 56 & $0.698(0.370-1.410)$ & 0.302 \\
\hline \multicolumn{4}{|l|}{ Metastatic site } \\
\hline Visceral & 34 & 1.00 & \\
\hline Non-visceral & 40 & $0.898(0.499-1.636)$ & 0.720 \\
\hline \multicolumn{4}{|c|}{$\begin{array}{l}\text { Adjuvant or neoadjuvant } \\
\text { chemotherapy }\end{array}$} \\
\hline No & 31 & 1.00 & \\
\hline Yes & 25 & $0.888(0.438-1.753)$ & 0.735 \\
\hline $\begin{array}{l}\text { Number of prior } \\
\text { chemotherapy reg } \\
\text { for advanced or } \\
\text { metastatic } \\
\text { breast cancer }\end{array}$ & & & \\
\hline 0 and 1 & 41 & 1.00 & \\
\hline 2 or more & 33 & $3.443(1.899-6.366)$ & $<0.0001$ \\
\hline \multicolumn{4}{|l|}{ NLR leveld } \\
\hline Low & 33 & 1.00 & \\
\hline High & 41 & $2.539(1.378-4.925)$ & 0.018 \\
\hline \multicolumn{4}{|l|}{ ALC levele } \\
\hline High & 21 & 1.00 & \\
\hline Low & 53 & $3.332(1.620-7.767)$ & 0.0007 \\
\hline \multicolumn{4}{|l|}{ CRP levelf } \\
\hline Low & 33 & 1.00 & \\
\hline High & 41 & $2.071(1.143-3.896)$ & 0.018 \\
\hline \multicolumn{4}{|l|}{ NLR/ALC ${ }^{\mathrm{d}, \mathrm{e}}$} \\
\hline Others & 37 & 1.00 & \\
\hline NLR-H/ALC-L & 37 & $3.178(1.733-6.087)$ & 0.0002 \\
\hline \multicolumn{4}{|l|}{ NLR/CRPd,f } \\
\hline Others & 45 & 1.00 & \\
\hline NLR-H/CRP-H & 29 & $2.173(1.212-3.899)$ & 0.010 \\
\hline \multicolumn{4}{|l|}{ ALC/CRPe,f } \\
\hline Others & 42 & 1.00 & \\
\hline ALC-L/CRP-H & 32 & $2.795(1.555-5.098)$ & 0.0006 \\
\hline
\end{tabular}

aHazard ratio (95\% confidence interval); ${ }^{b}$ One patient was male; ${ }^{\mathrm{c}}$ One patient had two tumors (positive and negative); HER2: human epidermal growth factor receptor 2; ER: estrogen receptor; $\mathrm{d}_{\text {neutrophil- }}$ to-lymphocyte ratio high $(\mathrm{H}): \geq 3$, low $(\mathrm{L}):<3$; eabsolute lymphocyte count high $(\mathrm{H}): \geq 1500 / \mu \mathrm{l}$, low $(\mathrm{L}):<1500 / \mu \mathrm{l}$; f $\mathrm{C}$-reactive protein high $(\mathrm{H}): \geq 0.3 \mathrm{mg} / \mathrm{dl}$, low $(\mathrm{L}):<0.3 \mathrm{mg} / \mathrm{dl}$. 
Table III. Multivariate analysis of overall survival.

\begin{tabular}{lccc}
\hline & $\mathrm{n}$ & HR $(95 \% \mathrm{CI})^{\mathrm{a}, \mathrm{b}}$ & $p$-Value \\
\hline $\begin{array}{l}\text { NLR levelc } \\
\text { Low }\end{array}$ & 33 & 1.00 & \\
$\quad$ High & 41 & $1.738(0.873-3.458)$ & 0.115 \\
ALC level & & \\
$\quad$ High & 21 & 1.00 & \\
Low & 53 & $1.444(0.551-3.785)$ & 0.455 \\
CRP levele & & & \\
Low & 33 & 1.00 & \\
$\quad$ High & 41 & $1.501(0.764-2.949)$ & 0.239 \\
NLR and ALC levelc,d & & & \\
$\quad$ Others & 37 & 1.00 & \\
$\quad$ NLR-H/ALC-L & 37 & $1.931(0.957-3.896)$ & 0.066 \\
NLR and CRP levelc,e & & & \\
$\quad$ Others & 45 & 1.00 & \\
$\quad$ NLR-H/CRP-H & 29 & $1.706(0.938-3.103)$ & 0.080 \\
ALC and CRP level ${ }^{\mathrm{d}, \mathrm{e}}$ & & & \\
$\quad$ Others & 42 & 1.00 & \\
ALC-L/CRP-H & 32 & $1.984(1.005-3.914)$ & 0.048 \\
\hline
\end{tabular}

aHazard ratio (95\% confidence interval); bAdjusted for menopausal status, subtypes, de novo or recurrent tumor, metastatic site, adjuvant or neoadjuvant chemotherapy, and number of prior chemotherapy regimens for advanced or metastatic breast cancer; ${ }^{c}$ neutrophil-to-lymphocyte ratio high $(\mathrm{H}): \geq 3$, low $(\mathrm{L}):<3$; dabsolute lymphocyte count high $(\mathrm{H})$ : $\geq 1500 / \mu 1$, low $(\mathrm{L}):<1500 / \mu \mathrm{l}$; ${ }^{\mathrm{C}} \mathrm{C}$-reactive protein high $(\mathrm{H}): \geq 0.3 \mathrm{mg} / \mathrm{dl}$, low (L): $<0.3 \mathrm{mg} / \mathrm{dl}$.

Similarly, NLR levels were significantly lower in the CRPlow group (median: 2.494; range $=0.826-12.224$ ) than in the CRP-high group (median: 3.761; range $=0.975-21.875$; $p=0.0007$; Figure $3 \mathrm{C}$ ). In contrast, there was no significant difference between ALC and CRP levels (median: 1179/ $\mu$; range $=190-2509 / \mu \mathrm{l}$ for CRP-low and median: 1032/ $\mu$; range $=322-2393 / \mu$ l for CRP-high; $p=0.1723$; Figure 3B).

\section{Discussion}

In the present study, we demonstrated that OS was significantly longer in patients treated with eribulin when their baseline NLR was low $(p=0.0027)$ or ALC was high $(p=0.0013)$. In addition, low levels of baseline CRP were significantly associated with longer OS $(p=0.0164)$. Combined analysis of these factors revealed that OS was significantly and independently shorter in patients with baseline low ALC and high CRP by multivariate analysis (adjusted HR=1.984; 95\% CI=1.005-3.914; $p=0.048$ ). These data might indicate that baseline levels of CRP improve the predictive accuracy of ALC for eribulin efficacy.

As previously mentioned, both NLR and ALC have been significantly associated with the prognosis of patients with MBC treated with eribulin (15-18). In line with these previous studies, we confirmed that baseline NLR
$(\mathrm{HR}=2.539 ; \quad 95 \% \mathrm{CI}=1.378-4.925 ; \quad p=0.018)$ and $\mathrm{ALC}$ $(\mathrm{HR}=3.332 ; 95 \% \mathrm{CI}=1.620-7.767 ; p=0.0007)$ were predictors of eribulin efficacy in terms of OS. According to the retrospective analysis in the prospective EMBRACE study, in which OS between eribulin and TPC groups were investigated, HRs in patients with ALC $\geq 1500 / \mu l$ and $<1500 / \mu \mathrm{l}$ were $0.586(95 \% \mathrm{CI}=0.437-0.784 ; p<0.001)$ and 1.002 (95\% CI $=0.800-1.253 ; p=0.989$; interaction, $p=0.003$ ), respectively (18). In contrast, the HRs in patients with NLR $\geq 3$ and $<3$ were $0.856(95 \% \mathrm{CI}=0.669-1.096 ; p=0.218)$ and 0.755 (95\% CI $=0.572-0.996 ; p=0.046$; interaction, $p=0.451$ ), respectively. These data strongly indicate the significance of ALC, but not NLR, as a specific predictive factor for eribulin because NLR levels were associated with OS not only in patients treated with eribulin, but also with TPC (18). Although it is not specific for eribulin, NLR may still be useful for identifying patients who could benefit from eribulin treatment.

Consistent with the report of Ueno et al. (17), our data indicate that the combination of NLR and ALC predicts OS more accurately than either marker alone (Figure 2A), although NLR and ALC were inversely correlated (data not shown). However, the combination of ALC and CRP were associated with OS most precisely, as shown in the present study (Figure 2C, Table III). As expected, the OS of patients in the ALC-high and CRP-low group ( $\mathrm{n}=13,2$-year OS, 0.795 ) was the longest, and that in the ALC-low and CRPhigh group ( $\mathrm{n}=32$, 2-yearr OS, 0.151) was the shortest. ALChigh and CRP-high patients $(\mathrm{n}=8,2$-year OS, 0.571) and ALC-low and CRP-low patients ( $\mathrm{n}=21,2$-year OS, 0.386) showed intermediate OS (Figure 2C). Multivariate analysis showed that the combination of ALC and CRP, but not NLR and ALC or NLR and CRP, was significantly and independently associated with OS (Table III).

In addition to NLR, CRP is a peripheral blood marker of inflammation and patients with high CRP levels have been repeatedly reported to have shorter OS (20-22). A significant association between elevated CRP levels and a higher incidence of breast cancer was also confirmed by the meta-analysis reported by Guo et al. (23). These studies suggest an important role for CRP in various stages of breast cancer from initiation and progression to metastasis. CRP is produced by several inflammatory cytokines, including interleukin-6 and tumor necrosis factor- $\alpha$ (24). It is evident that inflammation promotes tumor progression through angiogenesis, cancer-associated fibroblasts, tumor-associated macrophages, and neutrophil infiltration, resulting in a favorable microenvironment for breast cancer (25). At the same time, inflammation and immunity are tightly connected and contribute to tumor progression (26). Based on these observations, we speculate that higher levels of CRP represent a promoting microenvironment for tumor progression and an unfavorable immune microenvironment for breast cancer patients. 


\section{(A) Overall survival (NLR and ALC)}

NL/AH: $H R=0.265 ; 95 \% \mathrm{Cl}=0.106-0.575$

NL/AL: $\quad H R=0.455 ; 95 \% \mathrm{Cl}=0.184-0.975$

$\mathrm{NH} / \mathrm{AH}: \mathrm{HR}=0.162 ; 95 \% \mathrm{Cl}=0.009-0.756$

$p=0.0013$

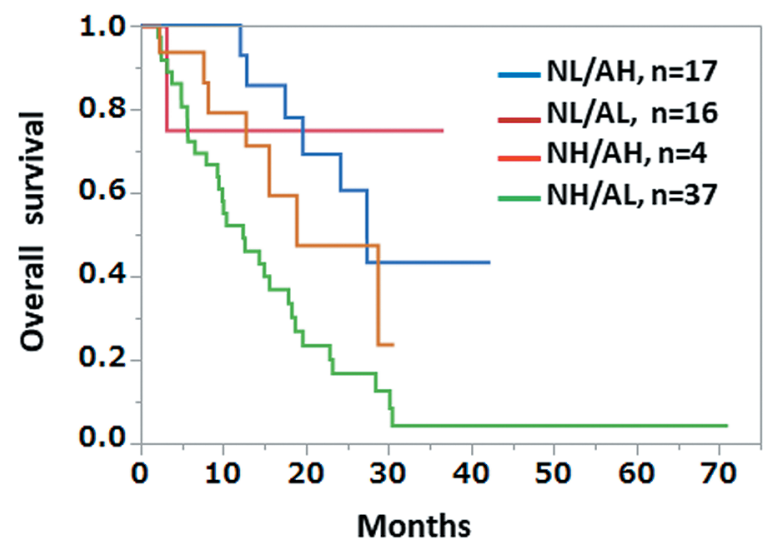

$\begin{array}{ccccccccc}\text { NL/AH } & 17 & 15 & 8 & 5 & 2 & 0 & 0 & 0 \\ \text { NL/AL } & 16 & 10 & 4 & 1 & 0 & 0 & 0 & 0 \\ \text { NH/AH } & 4 & 3 & 2 & 1 & 0 & 0 & 0 & 0 \\ \text { NH/AL } & 37 & 20 & 7 & 3 & 1 & 1 & 1 & 1\end{array}$

(B) Overall survival (NLR and CRP)

$\mathrm{NL} / \mathrm{CL} ; \mathrm{HR}=0.261 ; 95 \% \mathrm{Cl}=0.103-0.580$

$\mathrm{NL} / \mathrm{CH} ; \mathrm{HR}=0.598 ; 95 \% \mathrm{Cl}=0.237-1.327$

$\mathrm{NH} / \mathrm{CL} ; \mathrm{HR}=0.773 ; 95 \% \mathrm{Cl}=0.338-1.618$

$p=0.0112$

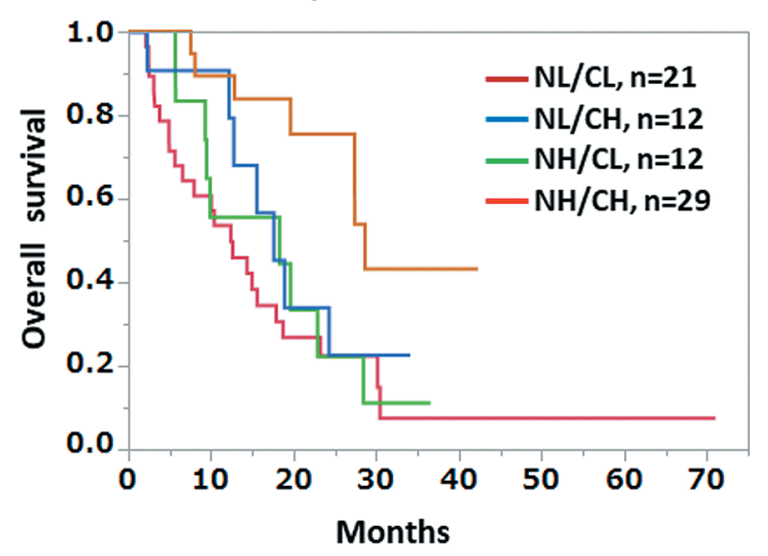

\section{(C) Overall survival (ALC and CRP)}

$\mathrm{AH} / \mathrm{CL} ; \mathrm{HR}=0.166 ; 95 \% \mathrm{Cl}=0.048-0.432$

$\mathrm{AH} / \mathrm{CH} ; \mathrm{HR}=0.400 ; 95 \% \mathrm{Cl}=0.118-1.034$

$\mathrm{AL} / \mathrm{CL} ; \mathrm{HR}=0.536 ; 95 \% \mathrm{Cl}=0.260-1.041$

$p=0.0013$

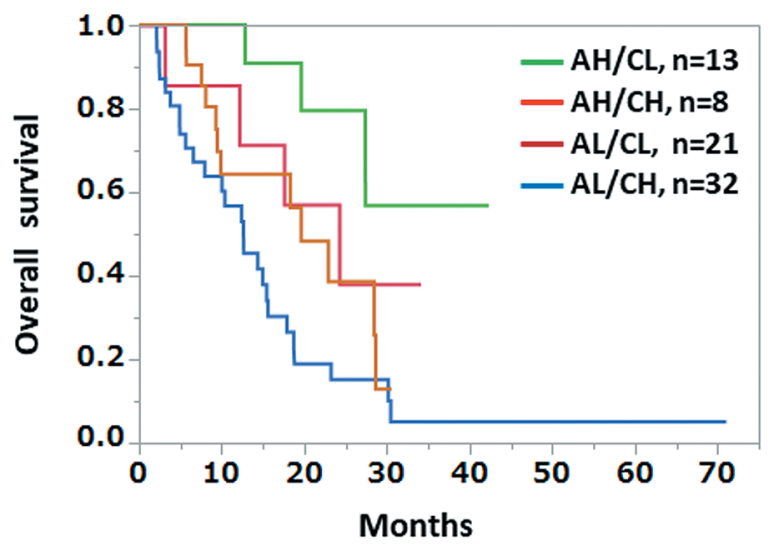

$\begin{array}{ccccccccc}\mathrm{AH} / \mathrm{CL} & 13 & 12 & 7 & 5 & 2 & 0 & 0 & 0 \\ \mathrm{AH} / \mathrm{CH} & 8 & 6 & 3 & 1 & 0 & 0 & 0 & 0 \\ \mathrm{AL} / \mathrm{CL} & 21 & 12 & 6 & 1 & 0 & 0 & 0 & 0 \\ \mathrm{AL} / \mathrm{CH} & 32 & 18 & 5 & 3 & 1 & 1 & 1 & 1\end{array}$

Figure 2. Overall survival (OS) of patients according to baseline levels of neutrophil-to-lymphocyte ratio (NLR) and absolute lymphocyte count $(A L C)(A)$. OS was significantly associated with NLR and ALC levels ( $p=0.0013)$. OS of patients according to baseline levels of NLR and C-reactive protein $(C R P)(B)$. OS was significantly associated with NLR and CRP levels ( $p=0.0112)$. OS of patients according to baseline ALC and C-reactive CRP levels $(C)$. OS was significantly associated with ALC and CRP levels $(p=0.0013)$. Neutrophil-to-lymphocyte ratio $(N)$, high $(H) \geq 3$, low $(L)$ $<3$; absolute lymphocyte count $(A)$, high $(H) \geq 1500 / \mu l$, low $(L)<1500 / \mu l$; C-reactive protein $(C)$, high $(H) \geq 0.3 \mathrm{mg} / \mathrm{dl}$ and low $(\mathrm{L})<0.3 \mathrm{mg} / \mathrm{dl}$. 


\section{(A) Neutrophil count}

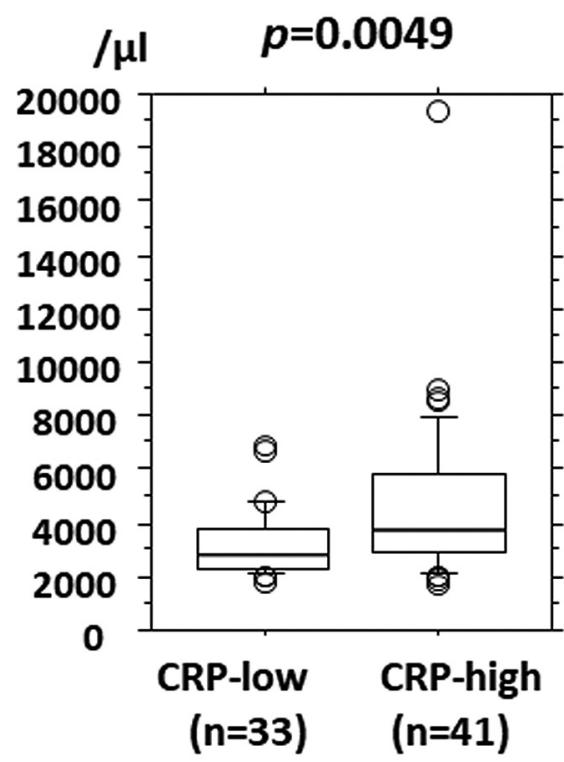

(B) Lymphocyte count

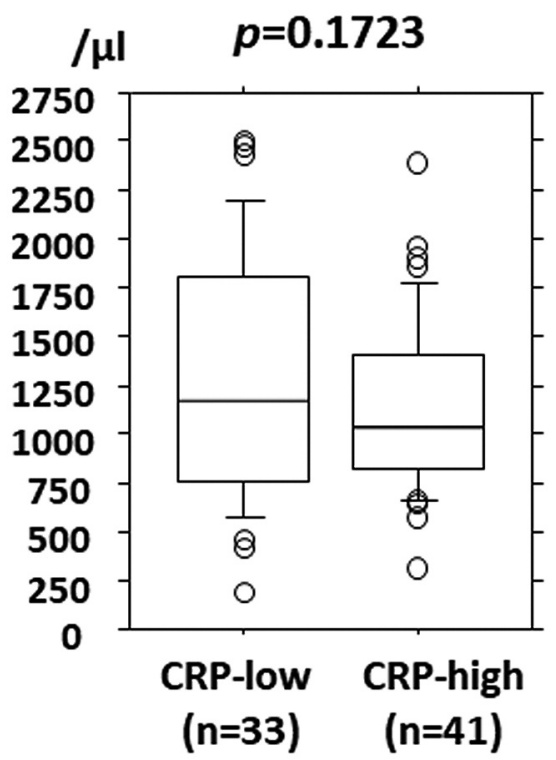

(C) Neutrophil-tolymphocyte ratio

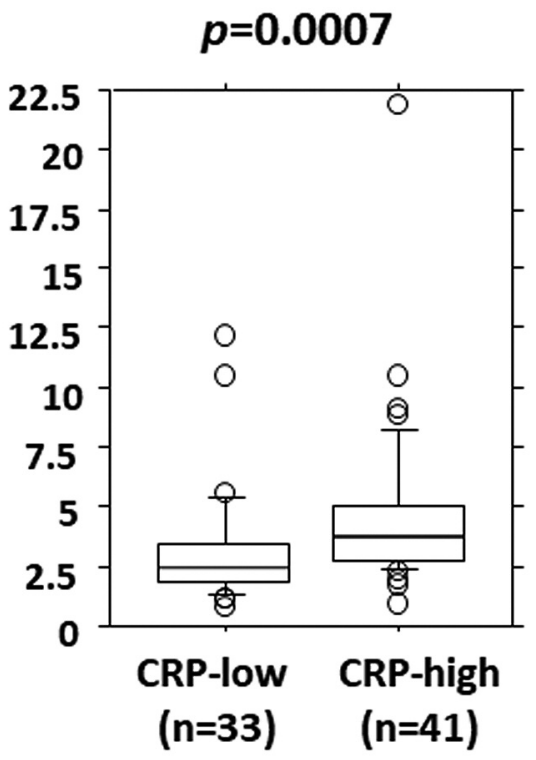

Figure 3. Absolute neutrophil count (A), absolute lymphocyte count (B), and neutrophil-to-lymphocyte ratio $(C)$ according to $C$-reactive protein $(C R P)$ levels. Neutrophil counts were significantly higher in patients with high CRP levels than in those with low CRP levels ( $p=0.0049)(A)$. Lymphocyte counts were not associated with CRP levels $(p=0.1723)(B) . N L R$ was significantly higher in patients with high CRP levels than in those with low NLR levels ( $p=0.0007)(C)$. CRP high $\geq 0.3 \mathrm{mg} / \mathrm{dl}$, low $<0.3 \mathrm{mg} / \mathrm{dl}$.

As demonstrated in the present study, NLR was significantly associated with CRP $(p=0.0007)$, but there was no significant association between ALC levels and CRP ( $p=0.1723$, Figure 3 ). We speculate that high levels of serum CRP represent an immunosuppressive microenvironment that is favorable for cancer progression $(25,26)$. Inflammation status in the tumor microenvironment, as indicated through CRP levels, may influence the immune reaction against breast cancer as evaluated by ALC levels. Based on these hypotheses, we believe that the combination of ALC and CRP can predict eribulin efficacy more precisely.

PFS was significantly longer in patients who received three chemotherapy regimens for advanced disease compared to those who had more than three chemotherapy regimens (median PFS, 8.6 months vs. 4.6 months; $p=0.008$ ) (27). Similarly, in a post-hoc pooled analysis of studies 305 and 301, which compared eribulin and TPC or capecitabine, patients with $\leq 3$ prior chemotherapy regimens had longer median OS with eribulin (15.3 vs. 13.2 months; $p=0.01)(28)$. Thus, on the basis of those data and data from the present study, we estimate that eribulin treatment has an impact on prognosis. NLR and ALC levels were significantly associated with the number of prior chemotherapy regimens (Table I). However, after multivariate analysis none of these factors were significant (Table III), suggesting that NLR and ALC could only be effective predictors on their own. In contrast, the combination of ALC and CRP was an independent predictive factor for eribulin by multivariate analysis including the number of previous chemotherapy regimens.

This study has several limitations. First, we retrospectively collected data from patients treated with eribulin and patients' backgrounds were not balanced in subgroups. Second, whether the predictive efficacy of the ALC and CRP combination is eribulin-specific is still unknown. These issues need to be confirmed in the future using prospective studies including a larger number of patients, and detailed experiments on immune markers.

In conclusion, we have demonstrated that baseline levels of CRP provide additional information on the predictive efficacy of ALC for improved OS induced by eribulin. These are widely available simple markers with low costs and might be useful in clinical practice for selecting patients who may benefit from eribulin treatment in terms of improved OS.

\section{Conflicts of Interest}

YaM received research funding and honoraria from Esai, Chugai, AstraZeneca, Eli Lilly, Pfizer, MSD, Kyowa-Kirin, and Taiho. The other Authors declare that they have no conflicts of interest related this study. 


\section{Authors' Contributions}

AS and YaM designed the study. AS, RF, YoM, AB, HO, YF, TH, and MI were involved in data collection. AS and YaM performed the statistical analyses. AS, and YaM prepared the manuscript. All Authors read and approved the final version of the manuscript.

\section{Acknowledgements}

The Authors would like to thank Editage (www.editage.jp) for English language editing.

\section{References}

1 National Comprehensive Cancer Network Clinical Practice Guidelines in Oncology (NCCN Guidelines ${ }^{\circledR}$ ). Breast Cancer. Version 3. 2020. Available at: https://www.nccn.org/professionals/ physician_gls/pdf/breast.pdf [Last accessed June 12, 2020]

2 Cortes J, O’Shaughnessy J, Loesch D, Blum JL, Vahdat LT, Petrakova K, Chollet P, Manikas A, Diéras V, Delozier T, Vladimirov V, Cardoso F, Koh H, Bougnoux P, Dutcus CE, Seegobin S, Mir D, Meneses N, Wanders J and Twelves C; EMBRACE (Eisai Metastatic Breast Cancer Study Assessing Physician's Choice Versus E7389) investigators: Eribulin monotherapy versus treatment of physician's choice in patients with metastatic breast cancer (EMBRACE): a phase 3 open-label randomised study. Lancet 377(9769): 914-923, 2011. PMID: 21376385. DOI: 10.1016/S0140-6736(11)60070-6

3 Kaufman PA, Awada A, Twelves C, Yelle L, Perez EA, Velikova G, Olivo MS, He Y, Dutcus CE and Cortes J: Phase III openlabel randomized study of eribulin mesylate versus capecitabine in patients with locally advanced or metastatic breast cancer previously treated with an anthracycline and a taxane. J Clin Oncol 33(6): 594-601, 2015. PMID: 25605862. DOI: 10.1200/ JCO.2013.52.4892

4 Pivot X, Marmé F, Koenigsberg R, Guo M, Berrak E and Wolfer A: Pooled analyses of eribulin in metastatic breast cancer patients with at least one prior chemotherapy. Ann Oncol 27(8): 15251531, 2016. PMID: 27177860. DOI: 10.1093/annonc/mdw 203

5 Twelves C, Cortes J, Vahdat L, Olivo M, He Y, Kaufman PA and Awada A: Efficacy of eribulin in women with metastatic breast cancer: a pooled analysis of two phase 3 studies. Breast Cancer Res Treat 148(3): 553-561, 2014. PMID: 25381136. DOI: 10.1007/s10549-014-3144-y

6 Yoshida T, Ozawa Y, Kimura T, Sato Y, Kuznetsov G, Xu S, Uesugi M, Agoulnik S, Taylor N, Funahashi Y and Matsui J: Eribulin mesilate suppresses experimental metastasis of breast cancer cells by reversing phenotype from epithelial-mesenchymal transition (EMT) to mesenchymal-epithelial transition (MET) states. Br J Cancer 110(6): 1497-1505, 2014. PMID: 24569463. DOI: $10.1038 /$ bjc. 2014.80

7 Kaul R, Risinger AL and Mooberry SL: Eribulin rapidly inhibits TGF- $\beta$-induced Snail expression and can induce Slug expression in a Smad4-dependent manner. Br J Cancer 121(7): 611-621, 2019. PMID: 31481735. DOI: 10.1038/s41416-019$0556-9$

8 Dybdal-Hargreaves NF, Risinger AL and Mooberry SL: Regulation of E-cadherin localization by microtubule targeting agents: rapid promotion of cortical E-cadherin through $\mathrm{p} 130 \mathrm{Cas} / \mathrm{Src}$ inhibition by eribulin. Oncotarget 9(5): 5545-5561, 2017. PMID: 29464017. DOI: 10.18632/oncotarget.23798

9 Funahashi Y, Okamoto K, Adachi Y, Semba T, Uesugi M, Ozawa Y, Tohyama O, Uehara T, Kimura T, Watanabe H, Asano M, Kawano S, Tizon X, McCracken PJ, Matsui J, Aoshima K, Nomoto $\mathrm{K}$ and Oda Y: Eribulin mesylate reduces tumor microenvironment abnormality by vascular remodeling in preclinical human breast cancer models. Cancer Sci 105(10): 1334-1342, 2014. PMID: 25060424. DOI: 10.1111/cas.12488

10 Ueda S, Saeki T, Takeuchi H, Shigekawa T, Yamane T, Kuji I and Osaki A: In vivo imaging of eribulin-induced reoxygenation in advanced breast cancer patients: a comparison to bevacizumab. Br J Cancer 114(11): 1212-1218, 2016. PMID: 27140309. DOI: 10.1038/bjc.2016.122

11 Kashiwagi S, Asano Y, Goto W, Takada K, Takahashi K, Hatano T, Tanaka S, Takashima T, Tomita S, Motomura H, Ohsawa M, Hirakawa $\mathrm{K}$ and Ohira M: Mesenchymal-epithelial transition and tumor vascular remodeling in eribulin chemotherapy for breast cancer. Anticancer Res 38(1): 401-410, 2018. PMID: 29277801.

12 Kashiwagi S, Asano Y, Goto W, Takada K, Morisaki T, Kouhashi R, Yabumoto A, Tanaka S, Takashima T, Ohsawa M, Hirakawa $\mathrm{K}$ and Ohira $\mathrm{M}$ : Validation of systemic and local tumour immune response to eribulin chemotherapy in the treatment of breast cancer. Anticancer Res 40(6): 3345-3354, 2020. PMID: 32487630. DOI: 10.21873 /anticanres.14317

13 Dieci MV, Tsvetkova V, Orvieto E, Piacentini F, Ficarra G, Griguolo G, Miglietta F, Giarratano T, Omarini C, Bonaguro S, Cappellesso R, Aliberti C, Vernaci G, Giorgi CA, Faggioni G, Tasca G, Conte P and Guarneri V: Immune characterization of breast cancer metastases: prognostic implications. Breast Cancer Res 20(1): 62, 2018. PMID: 29929548. DOI: 10.1186/s13058018-1003-1

14 Goto W, Kashiwagi S, Asano Y, Takada K, Morisaki T, Fujita H, Takashima T, Ohsawa M, Hirakawa K and Ohira M: Eribulin promotes antitumor immune responses in patients with locally advanced or metastatic breast cancer. Anticancer Res 38(5): 29292938, 2018. PMID: 29715119. DOI: 10.21873/anticanres.12541

15 Miyagawa Y, Araki K, Bun A, Ozawa H, Fujimoto Y, Higuchi T, Nishimukai A, Kira A, Imamura M, Takatsuka Y and Miyoshi Y: Significant association between low baseline neutrophil-tolymphocyte ratio and improved progression-free survival of patients with locally advanced or metastatic breast cancer treated with eribulin but not with nab-paclitaxel. Clin Breast Cancer 18(5): 400409, 2018. PMID: 29605174. DOI: 10.1016/j.clbc.2018.03.002

16 Myojin M, Horimoto Y, Ito M, Kitano S, Ishizuka Y, Sasaki R, Uomori T, Himuro T, Murakami F, Nakai K, Iijima K and Saito M: Neutrophil-to-lymphocyte ratio and histological type might predict clinical responses to eriburin-based treatment in patients with metastatic breast cancer. Breast Cancer, 2020. PMID: 32108306. DOI: 10.1007/s12282-020-01069-0

17 Ueno A, Maeda R, Kin T, Ito M, Kawasaki K and Ohtani S: Utility of the absolute lymphocyte count and neutrophil/lymphocyte ratio for predicting survival in patients with metastatic breast cancer on eribulin: a real-world observational study. Chemotherapy 1-11, 2020. PMID: 32305977. DOI: 10.1159/000507043

18 Miyoshi Y, Yoshimura Y, Saito K, Muramoto K, Sugawara M, Alexis K, Nomoto K, Nakamura S, Saeki T, Watanabe J, PerezGarcia JM and Cortes J: High absolute lymphocyte counts are associated with longer overall survival in patients with metastatic breast cancer treated with eribulin-but not with 
treatment of physician's choice-in the EMBRACE study. Breast Cancer, 2020. PMID: 32133606. DOI: 10.1007/s12282-02001067-2

19 Han Y, Mao F, Wu Y, Fu X, Zhu X, Zhou S, Zhang W, Sun Q and Zhao Y: Prognostic role of C-reactive protein in breast cancer: a systematic review and meta-analysis. Int J Biol Markers 26(4): 209-215, 2011. PMID: 22139643. DOI: 10.5301/JBM.2011.8872

20 Allin KH, Nordestgaard BG, Flyger H and Bojesen SE: Elevated pre-treatment levels of plasma C-reactive protein are associated with poor prognosis after breast cancer: a cohort study. Breast Cancer Res 13(3): R55, 2011. PMID: 21639875. DOI: 10.1186/ bcr2891

21 Petekkaya I, Unlu O, Roach EC, Gecmez G, Okoh AK, Babacan T, Sarici F, Keskin O, Arslan C, Petekkaya E, Sever AR and Altundag K: Prognostic role of inflammatory biomarkers in metastatic breast cancer. J BUON 22(3): 614-622, 2017. PMID: 28730765.

22 Kaur RP, Rubal, Banipal RPS, Vashistha R, Dhiman M and Munshi A: Association of elevated levels of C-reactive protein with breast cancer, breast cancer subtypes, and poor outcome. Curr Probl Cancer 43(2): 123-129, 2019. PMID: 29921457. DOI: $10.1016 /$ j.currproblcancer.2018.05.003

23 Guo L, Liu S, Zhang S, Chen Q, Zhang M, Quan P, Lu J and Sun X: C-reactive protein and risk of breast cancer: A systematic review and meta-analysis. Sci Rep 5: 10508, 2015. PMID: 26001129. DOI: $10.1038 /$ srep 10508
24 Mahmoud FA and Rivera NI: The role of C-reactive protein as a prognostic indicator in advanced cancer. Curr Oncol Rep 4(3): 250-255, 2002. PMID: 11937016.

25 Coussens LM and Werb Z: Inflammation and cancer. Nature 420(6917): 860-867, 2002. PMID: 12490959.

26 Grivennikov SI, Greten FR and Karin M: Immunity, inflammation, and cancer. Cell 140(6): 883-899, 2010. PMID: 20303878. DOI: $10.1016 /$ j.cell.2010.01.025

27 Oruc Z, Kaplan MA, Geredeli C, Yildirim Sari N, Ozaslan E, Aytekin A, Tamer Elkiran E, Koca S, Dogan M, Turan N, Yuce $\mathrm{O}$, Sevinc A, Ercelep $\mathrm{O}$ and Isikdogan A: Is eribulin treatment prognostic factor in patients with metastatic breast cancer treated with this drug? Retrospective analysis of a multicentre study. J BUON 24(5): 1876-1883, 2019. PMID: 31786850.

28 Cortes $\mathrm{J}$ and Twelves $\mathrm{C}$ : Impact of the number of prior chemotherapy regimens on outcomes for patients with metastatic breast cancer treated with eribulin: A post hoc pooled analysis. Breast J, 2019. PMID: 31782589. DOI: 10.1111/tbj.13686

Received May 28, 2020

Revised June 16, 2020

Accepted June 17, 2020 